\title{
FINANCIAMENTO ESTUDANTIL NA AUSTRÁLIA \\ E NOS ESTADOS UNIDOS: LIÇÕES PARA O BRASIL ${ }^{1}$
}

Paulo Meyer Nascimento²

Manoela Vilela Araújo Resende ${ }^{3}$

\section{INTRODUÇÃO}

Brasil, Austrália e Estados Unidos são países que guardam grandes diferenças entre si, mas também algumas similaridades. Os três são repúblicas federativas, grandes economias e naçôes com alto grau de diversidade étnica e cultural. Para fins de políticas de ensino superior, contudo, a maior similaridade está no fato de que nos três há grande protagonismo do governo federal em questôes de financiamento e de regulação. Este fato facilita a comparaçáo dos sistemas de financiamento de estudantes de ensino superior dos três países, destacando suas respectivas peculiaridades e discutindo em que medida a experiência de cada um deles pode ser relevante para os outros dois.

Tendo por foco o financiamento do ensino, ${ }^{4}$ o objetivo deste texto é discutir quais características dos sistemas federais australiano e norte-americano poderiam inspirar inovaçóes no sistema brasileiro e quais deveriam ser evitadas. Em busca desse objetivo, a seção 2 e o apêndice fornecem um sumário dos modelos vigentes no Brasil, na Austrália e nos Estados Unidos para financiar estudantes de ensino superior, para, daí, serem discutidas, na seção 3, também de maneira sucinta, as liçôes advindas dos dois modelos estrangeiros que poderiam ser aproveitadas no Brasil.

\section{COMPARANDO OS TRÊS SISTEMAS}

Quando falamos de financiamento de estudantes de ensino superior no Brasil imaginam-se, logo, programas de bolsa ou de empréstimos para ajudar estudantes carentes a pagar as mensalidades de cursos superiores em instituiçóes privadas de ensino. Esse é o pensamento que aflora de imediato porque, aqui, o ensino superior é gratuito em instituiçóes públicas 5 e porque é recorrente o debate sobre iniciativas governamentais como o Programa Universidade para Todos (Prouni) e o Programa de Financiamento Estudantil (Fies); o primeiro é um programa de bolsas, enquanto o segundo é um programa de crédito educativo, ambos desenhados para estudantes oriundos de famílias de baixa renda matriculados em cursos superiores pagos.

\footnotetext{
1. Este texto é uma versão resumida de um capítulo de livro (atualmente no prelo). Os autores agradecem à professora doutora Ana Maria de Albuquerque Moreira, do Departamento de Planejamento e Administração da Faculdade de Educação (PAD/FE) da Universidade de Brasília (UnB), pelo convite e pelo estímulo para que o produzissem a partir de suas pesquisas de doutorado (no caso de Paulo Meyer Nascimento) e de mestrado (no caso de Manoela Vilela Araújo Resende). Ressalte-se que as opiniões expressadas ao longo deste texto, bem como eventuais erros e omissões, são de inteira e exclusiva responsabilidade dos autores, não refletindo necessariamente posicionamento das instituições públicas das quais são servidores.

2. Técnico de planejamento e pesquisa na Diretoria de Estudos e Políticas Setoriais de Inovação e Infraestrutura (Diset) do Ipea. E-mail: < paulo.nascimento@ipea.gov.br>.

3. Analista técnico de políticas sociais no Ministério da Educação (MEC), atuando, em 2018, na Assessoria Estratégica de Evidências, no Gabinete do Ministro. E-mail: <manoelaaraujo@mec.gov.br>.
}

4. 0 financiamento à pesquisa, conquanto igualmente importante, não é objeto deste texto.

5. À exceção das instituições públicas que já cobravam mensalidades quando da promulgação da Constituição Federal de 1988 (CF/88). 
Tal qual no Brasil, bolsas e empréstimos são as modalidades de financiamento estudantil presentes mundo afora. Diferentemente do Brasil, contudo, cursos em instituiçôes de ensino superior (IES) públicas não são necessariamente gratuitos em outros países. Pelo contrário; o mais comum é exigir algum tipo de contribuição financeira de quem estuda, seja durante o curso, seja após a formatura.

Nos Estados Unidos e na Austrália, as IES públicas podem cobrar por seus cursos de graduação, o que não significa que não recebam aportes de recursos públicos. Isso ocorre nos Estados Unidos de variadas maneiras, a depender do ente federativo a que cada IES está vinculada e da sua capacidade para captar recursos externos. Já na Austrália, aportes públicos sobrevêm tanto por meio de repasses orçamentários diretos (tabelados por curso e proporcionais ao número de matrículas) quanto por meio de subsídios às contribuiçóes financeiras dos egressos. Seja nas públicas, seja nas privadas, norte-americanos e australianos cursando ensino superior dispóem de alternativas de financiamento público.

Via de regra, IES norte-americanas são livres para definir o valor das anuidades de seus cursos. Diversas modalidades de bolsas e empréstimos coexistem, alocadas por meio de um complexo sistema que, embora centralizado no nível federal, depende também de decisóes das IES e exige do estudante interessado, por vezes recorrentemente, grande número de informaçôes pessoais e familiares.

Já o sistema de financiamento estudantil australiano é bem mais simples e envolve unicamente empréstimos com amortizaçôes contingentes à renda futura (ECRs), com algumas variaçôes a depender da modalidade de ensino (profissional ou superior), da natureza administrativa da IES (pública ou privada) e do tipo de despesa financiada (anuidades do curso, outras taxas ou participação em programas de intercâmbio). O governo australiano estipula os valores máximos das anuidades de cada curso de IES pública e estabelece um limite para a quantia que estudantes de IES privadas podem tomar emprestado. O governo paga às IES no ato da matrícula, para depois o órgáo australiano equivalente à Receita Federal recolher pagamentos contingentes à renda do indivíduo, até que seja zerado seu saldo devedor, sendo perdoadas as dívidas estudantis porventura remanescentes em caso de morte. As taxas de juros dos empréstimos são subsidiadas na Austrália, mas em regra não o são nos Estados Unidos.

Por sua vez, no Brasil são diversos os sistemas públicos de financiamento de estudantes de ensino superior. A Uniâo, a maioria dos estados e alguns poucos municípios tanto ofertam vagas de ensino superior (por meio de suas IES) quanto financiam estudantes matriculados em cursos pagos. No caso da União, há ainda os subsídios na forma de restituições de imposto de renda para despesas privadas com educação. Apesar da atuação também de estados e municípios, há um protagonismo da União no financiamento público do ensino superior no Brasil, pois mantém as instituiçóes federais e opera políticas que geram subsídios para as privadas e eventualmente viabilizam recursos federais para IES estaduais e municipais.

Para estudantes matriculados em IES estaduais ou federais, a matrícula é $100 \%$ custeada por orçamentos públicos (respectivamente dos estados e da Uniáo). Costuma haver, ainda, alguma provisão orçamentária específica e bastante limitada, dos governos ou das próprias IES, para oferecer alimentação, alojamento e transporte subsidiados, preferencialmente a estudantes de baixa renda. Para estudantes matriculados nas IES privadas, o Fies ${ }^{6}$ o Prouni são os principais programas governamentais de assistência financeira.

\section{QUE LIÇÕES DOS SISTEMAS DA AUSTRÁLIA E DOS ESTADOS UNIDOS PODERIAM SER TIRADAS PARA O BRASIL?}

Há, nos sistemas federais de financiamento de estudantes do ensino superior da Austrália e dos Estados Unidos, tanto características positivas quanto negativas. Um olhar sobre elas pode trazer liçóes pertinentes ao Brasil, não apenas sobre o que fazer, mas, principalmente, sobre o que evitar. 
O aspecto positivo que mais merece atenção é o modelo de financiamento contingente à renda futura. O sistema australiano já funciona há trinta anos e tem demonstrado que, quando de ampla cobertura, com gestão centralizada e envolvendo a autoridade fiscal na coleta de pagamentos contingentes à renda, programas governamentais de financiamento estudantil conseguem conciliar sustentabilidade fiscal com acesso equitativo ao ensino superior.

O sistema norte-americano, sendo uma complexa teia de empréstimos e bolsas, tem poucas características positivas a serem aproveitadas. Pesquisas sugerem que a complexidade do sistema norte-americano dificulta acesso ao financiamento federal. ${ }^{7}$ Simplicidade é importante, mas esta é uma característica que nem o sistema norte-americano nem o brasileiro apresentam. Ademais, quem não consegue uma bolsa e não tem condiçôes de pagar por um curso superior nos Estados Unidos não dispóe de alternativas de crédito educativo que efetivamente proteja contra dificuldades de pagamento causadas por intempéries futuras no mercado de trabalho (desemprego e subemprego, por exemplo). As modalidades-padrão de crédito educativo não são contingentes à renda. As que são, exigem recadastramento anual e equiparam a dívida eventualmente perdoada (o que acontece se há débitos pendentes após 20 ou 25 anos, a depender do plano) à renda pessoal tributável. Portanto, quem não obtém meios para pagar nunca chega a ver sua dívida estudantil perdoada, na melhor das hipóteses ela é substituída por uma dívida tributária.

Como aspecto positivo, o sistema norte-americano é bem integrado; um ativo que falta ao sistema brasileiro. Embora tanto o Prouni quanto o Fies sejam programas federais, há sobreposição entre eles. Integrá-los traria ganhos de eficiência, que se amplificariam se o Fies viesse a se tornar, efetivamente, um ECR. Para que isso ocorra, seria necessário retirar a exigência de pagamento mínimo, que compromete o componente de proteção social desejável em um ECR, e envolver a Receita Federal na coleta dos reembolsos, automatizando o desconto em folha e expandindo a cobrança para outras fontes de renda. Deve-se evitar, contudo, juro real zero, pois implica elevados custos ao governo e beneficia até quem futuramente vier a ter alto padrão de renda, quando o ECR já protege os mais pobres. Com um ECR a pleno funcionamento, Prouni e Fies poderiam ser fundidos, já que egressos com salários baixos ao longo da vida eventualmente têm parte ou mesmo a totalidade de suas dívidas perdoadas, casos em que o ECR funciona como uma bolsa concedida a posteriori. Enquanto coexistissem, a integração permitiria um melhor direcionamento de estudantes de mais baixa renda ao Prouni e os demais ao Fies, focalizando melhor a ajuda federal.

Pode-se dizer, com razão, que as realidades australiana, brasileira e americana são muito diferentes. Essas diferenças dificultariam replicar no Brasil muitas das políticas públicas bem-sucedidas nesses países. No entanto, a integração das políticas federais de financiamento estudantil e a implementação de um ECR eficaz e sustentável são factíveis para o Brasil. As principais reformas legislativas para transformar o Fies em um ECR já foram feitas, restando ajustes finos no desenho do programa e o envolvimento da Receita Federal na coleta dos pagamentos. Um amplo e bem desenhado ECR poderia ajudar, ainda, a reposicionar o recorrente debate acerca da manutenção ou não da gratuidade em IES públicas, pois coloca em pauta uma alternativa que concilia gratuidade durante os estudos com contribuição financeira de acordo com a capacidade de pagamento dos egressos do sistema de ensino. 


\section{APÊNDICE}

TABELA A. 1

Principais características dos sistemas de financiamento estudantil do Brasil, da Austrália e dos Estados Unidos

\begin{tabular}{|c|c|c|c|}
\hline & Brasil & Austrália & Estados Unidos \\
\hline Modalidades de financiamento & $\begin{array}{l}\text { Gratuidade para todos matriculados em } \\
\text { IES públicas. Bolsas e empréstimos em } \\
\text { IES privadas, somente para } \\
\text { alunos elegíveis. }\end{array}$ & Empréstimos estudantis. & $\begin{array}{l}\text { Sistema integrado (e complexo) de } \\
\text { bolsas e empréstimos. Gratuidade em } \\
\text { (poucas) IES públicas, somente para } \\
\text { alunos elegíveis. }\end{array}$ \\
\hline Percentual de matrículas em IES públicas & $25 \%$ & $82 \%$ & $76 \%$ \\
\hline $\begin{array}{l}\text { IES elegíveis para empréstimos } \\
\text { estudantis }\end{array}$ & $\begin{array}{l}\text { Somente privadas (até } 2017 \text { ). Privadas } \\
\text { e autarquias estaduais e municipais (a } \\
\text { partir de 2018). }\end{array}$ & Públicas e privadas. & Públicas e privadas. \\
\hline Modalidade de amortização' & $\begin{array}{l}\text { EAT (até 2017) } \\
\text { ECR (a partir de 2018) }\end{array}$ & ECR & Padrão: EAT; ECR em casos especiais. \\
\hline Prazo de carência & $\begin{array}{l}\text { Dezoito meses após conclusão do curso } \\
\text { (até 2017) } \\
\text { Não há carência (a partir de 2018) }\end{array}$ & $\begin{array}{l}\text { Não há. Amortização automática, } \\
\text { ocorrendo sempre que a renda supera } \\
\text { limite de isenção. }\end{array}$ & Seis meses após conclusão do curso. \\
\hline Prazo máximo de amortização & $\begin{array}{l}\text { Três vezes a duração do curso + } 12 \\
\text { meses (até 2017) } \\
\text { Não definido (a partir de 2018) }\end{array}$ & Variável & Padrão: 10 anos; pode chegar a 25. \\
\hline Valor máximo de financiamento & Até $\mathrm{R} \$ 42$ mil por semestre & Variável & Variável \\
\hline Taxa nominal de juros & $\begin{array}{l}\text { 6,5\% a.a. (até } 2017 \text { ) } \\
\text { Variável. Principal modalidade atualiza } \\
\text { saldo devedor pela inflação (a partir de } \\
2018 \text { ) }\end{array}$ & Saldo devedor atualizado pela inflação & $4,45 \%$ a.a. \\
\hline Taxa de inadimplência² & $40,7 \%$ & $18 \%$ & $14 \%$ a $20 \%$ \\
\hline $\begin{array}{l}\text { Critérios para a concessão de emprés- } \\
\text { timo estudantil }\end{array}$ & Renda familiar e desempenho no Enem & Não há & $\begin{array}{l}\text { Critério de renda para a modalidade } \\
\text { subsidiada e para o } \mathrm{ECR}^{3}\end{array}$ \\
\hline
\end{tabular}

Elaboração dos autores.

Notas: ${ }^{1}$ EAT: empréstimos com amortizações a termo; ECR: empréstimos com amortizações contingentes à renda futura.

2 Dados reportados em relatórios oficiais. No caso australiano, o dado não se refere à taxa de inadimplência, mas sim à proporção de dívida que não será paga, também chamada de dívida incerta. No caso norte-americano, considera-se inadimplência atrasos superiores a 270 dias. No caso brasileiro, atrasos superiores a noventa dias (baixa probabilidade de recuperação, segundo o Banco Central). Aplicando-se ao Brasil a mesma definição utilizada nos Estados Unidos, a taxa de inadimplência seria próxima a 30\%.

${ }^{3}$ O financiamento estudantil padrão nos Estados Unidos pode ser subsidiado ou não subsidiado. No subsidiado, alunos com comprovada necessidade financeira não pagam os juros do empréstimo enquanto matriculados. Na modalidade não subsidiada, incidem juros mesmo durante a fase de utilização (matrícula). Quem enfrenta dificuldades para pagar sua dívida estudantil pode solicitar migração para o plano contingente à renda. 